\title{
Analysis of surgical emergencies in Benghazi, Libyan Arab Jamahiriya
}

\author{
A.A. Alshektheria, ${ }^{7}$ A.A. Salam, ${ }^{7}$ A.M. Bushala, ${ }^{7}$ M.A. Omer ${ }^{7}$ and R. Elwarfaly ${ }^{7}$
}

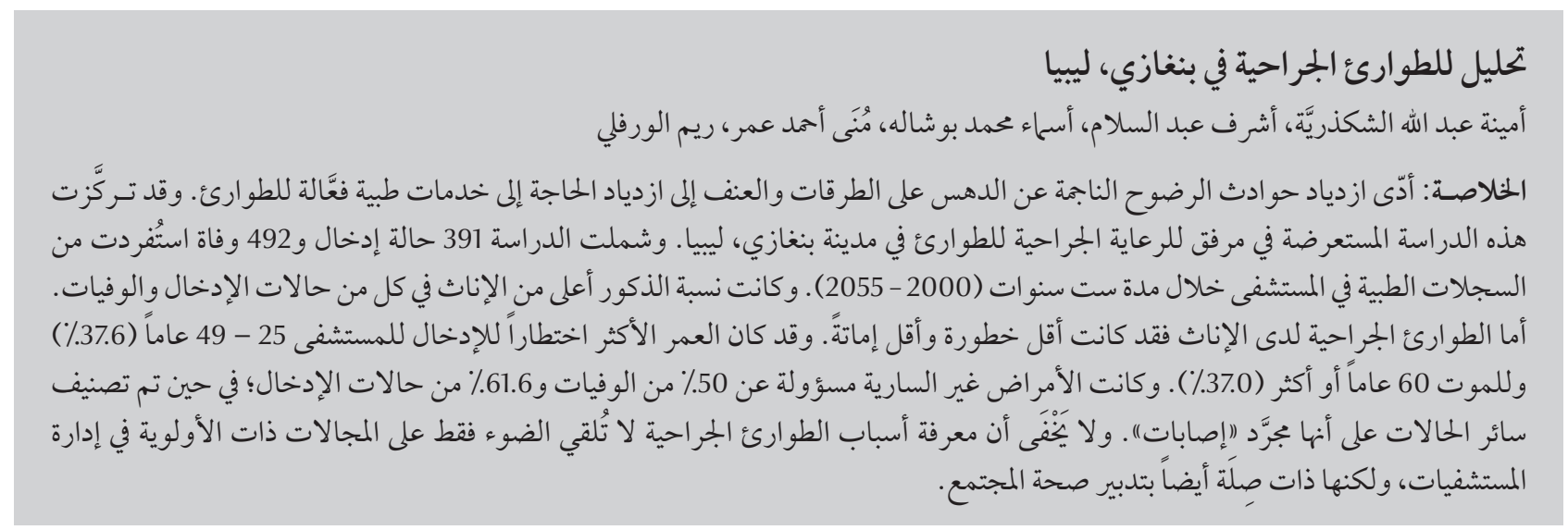

ABSTRACT The increasing incidence of trauma due to road crashes and violence has increased the need for an efficient emergency medical service. This cross-sectional study was based in a surgical emergency care facility in Benghazi city, Libyan Arab Jamahiriya. A representative sample of 391 admissions and 492 deaths was drawn from hospital medical records over a 6-year period (2000-05). A higher proportion of patients were males among both deaths and admissions. Surgical emergencies for females were less serious and less likely to be fatal. The most vulnerable age for admissions was 25-49 years (37.6\%) and for deaths was 60+ years (37.0\%). Noncommunicable diseases were responsible for $50.0 \%$ of deaths and $61.6 \%$ of admissions; the remainder were classified as injuries. The causes of surgical emergencies not only highlight priority areas for hospital management but also have relevance for community health management.

\section{Analyse des urgences chirurgicales à Benghazi (Jamahiriya arabe libyenne)}

RÉSUMÉ L'incidence croissante des traumatismes dus aux accidents de la route et à la violence a accentué la nécessité d'un service médical d'urgence efficace. La présente étude transversale a été conduite dans un établissement de soins chirurgicaux d'urgence de la ville de Benghazi (Jamahiriya arabe libyenne). Un échantillon représentatif de 391 admissions et 492 décès a été sélectionné à partir des dossiers médicaux de l'hôpital, sur une période de 6 ans allant de 2000 à 2005. Les patients de sexe masculin étaient plus nombreux parmi les admissions et les décès à I'hôpital. Les urgences chirurgicales chez les femmes étaient moins graves et moins susceptibles de conduire au décès. La tranche d'âge de 25 ans à 49 ans était la plus à risque pour les admissions (37,6 \%), alors que chez les plus de 60 ans, le risque de décès était plus élevé (37,0\%). Les maladies non transmissibles étaient responsables de 50,0\% des décès et de 61,6\% des admissions, les traumatismes représentant le pourcentage restant. Les causes des urgences chirurgicales attirent l'attention sur les domaines prioritaires pour la gestion hospitalière mais s'avèrent aussi pertinentes pour la gestion de la santé communautaire. 


\section{Introduction}

Surgical emergency and trauma care facilities are a medical innovation in tertiary care that address crisis situations requiring urgent attention. They also support populations distressed by disasters. The increasing incidence of trauma due to road traffic accidents (RTAs) and acute illnesses resulting from violence has increased the need for an efficient emergency medical service system. Emergency surgical cases are caused by a rise in life-threatening noncommunicable diseases (NCDs), e.g. gallbladder disease, gastrointestinal bleeding, appendicitis, heart disease, aneurism, stroke and complications associated with procedures, devices, implants or grafts $[1]$.

Understanding the workload of surgical emergency and trauma care centres facilitates decisions about the number and size of clinical departments [2], staffing, technologies, raw materials, drugs and medical consumables [3]. It is also of important for planning and developing hospital services [4], facilitating evaluation protocols for medical and administrative routine of emergency care facilities, especially quality of care and cost [5], and developing diagnostic or management techniques to prevent adverse events, such as medication side-effects and complications related to minor procedures [6].

In the Libyan Arab Jamahiriya emergencies in childhood result from acute respiratory infection, gastroenteritis, meningitis, diseases of the urinary system, acute poisoning and symptoms, congenital malformations and prematurity and ill-defined conditions [7]. Emergency hospital registers from Benghazi city show an increasing incidence of lifestyle diseases, e.g. diabetes, especially among the younger ages [8]; burn cases [9]; and cancer, mainly malignant lymphoma, nonHodgkin's lymphoma and Hodgkin's disease [10]. RTA fatalities have been rising rapidly in the Middle East and North Africa in the last 2 decades as compared with other regions in the world [11]; such incidents take a toll on the surgical emergency services in the city.

We analysed the medical records of a tertiary level surgical emergency and trauma hospital in Benghazi. The aim was to map the profile of surgical emergencies in the community and provide evidence to inform policymakers concerned with facility management.

\section{Methods}

\section{Study setting}

Benghazi, the second largest city in the Libyan Arab Jamahiriya, has a population of 636992 . As far as health infrastructure is concerned, there are facilities for primary care (polyclinics, health centres and units), secondary care (polyclinics and general hospitals) and tertiary care (regional hospitals and specialized centres). Al Jala surgical and trauma hospital is one of the tertiary care services that specializes in emergency care and caters to a population living in and around the city regardless of nationality. This hospital has a total capacity of 500 inpatient beds, 4 major operating rooms, 3 emergency operating rooms and 3 orthopaedic surgery rooms and has specialized departments for general surgery, orthopaedic surgery, neurology, cardiovascular surgery, orofacial surgery, plastic surgery and dental surgery. The hospital has a well functioning public health department, social workers and a hospital statistics division.

Al Jala hospital admitted a total of 95494 patients from 2000 to 2005 , of whom 82739 were discharged to attend the outpatient departments (Table 1). It is assumed that treatment outcomes of these patients were satisfactory. The number of patients who died in the hospital during the 2000-05 period was 2718 . The remaining patients either discharged themselves or left against medical advice or were transferred to hospitals outside Benghazi.

\section{Sample and data collection}

Samples from the records of admissions and deaths were selected for this current analysis. The sample size was calculated at the $5 \%$ level of significance and $95 \%$ confidence level. Cases were selected from registers using a simple random sampling method. A sample of 391 admissions to the hospital during the 6-year period 2000-01 and 2003-05 was selected from admissions records (admissions during 2002 were excluded from analysis as the records were incomplete at the time of this study). The second sample was 492 deaths in the hospital from 2002 to 2005.

Simple descriptive statistics were used to analyse the data.

\begin{tabular}{|c|c|c|c|}
\hline \multicolumn{4}{|c|}{$\begin{array}{l}\text { Table } 1 \text { Total admissions and deaths at a surgical emergency care facility in } \\
\text { Benghazi city, Libyan Arab Jamahiriya by year }\end{array}$} \\
\hline \multirow[t]{2}{*}{ Year } & \multicolumn{3}{|c|}{ No. of cases } \\
\hline & Admissions & Discharges & Deaths \\
\hline 2000 & 15797 & 13861 & 385 \\
\hline 2001 & 16386 & 13862 & 464 \\
\hline 2002 & 14586 & 12759 & 306 \\
\hline 2003 & 16242 & 14120 & 626 \\
\hline 2004 & 16038 & 14173 & 344 \\
\hline 2005 & 16445 & 13964 & 593 \\
\hline Total & 95494 & 82739 & 2718 \\
\hline
\end{tabular}




\section{Results}

\section{Sample characteristics}

The proportion of males was higher than females in both the samples from death records (67.3\% vs $32.7 \%$ ) and from admissions records ( $59.1 \%$ vs $38.6 \%$ ) (Table 2). Therefore males were a higher proportion of the death statistics than the admissions (67.3\% vs 59.1\%), while females were a higher proportion among admissions than deaths (38.6\% vs $32.7 \%$ ). Analysing the data by age showed that the highest rate of admissions was among those aged $25-49$ years (37.6\%); for deaths it was the age group $60+$ years $(37.0 \%)$ (Table 2$)$

\section{NCDs versus injuries}

The type of emergency condition was divided for analysis into NCDs and injuries. NCDs were responsible for 246 (50.0\%) deaths and 241 admissions $(61.6 \%)$, whereas injuries were responsible for 236 deaths (48.0\%), as against 126 admissions (32.2\%) (data were missing for some cases).

There was a significant association between age and type of surgical emergency condition $\left(\chi^{2}=22.3, P<0.01\right)$. NCDs were the major cause of death in the 60+ age group (62.1\%) (Table 3 ), whereas nearly two-thirds of deaths

\begin{tabular}{|c|c|c|c|c|}
\hline \multirow[t]{2}{*}{ Variable } & \multicolumn{2}{|c|}{$\begin{array}{l}\text { Admissions } \\
\quad(n=391)\end{array}$} & \multicolumn{2}{|c|}{$\begin{array}{l}\text { Deaths } \\
(n=492)\end{array}$} \\
\hline & No. & $\%$ & No. & $\%$ \\
\hline \multicolumn{5}{|l|}{ Sex } \\
\hline Male & 231 & 59.1 & 331 & 67.3 \\
\hline Female & 151 & 38.6 & 161 & 32.7 \\
\hline Missing data & 9 & 2.3 & 0 & 0.0 \\
\hline \multicolumn{5}{|l|}{ Age (years) } \\
\hline$<15$ & 70 & 17.9 & 43 & 8.7 \\
\hline $15-24$ & 80 & 20.5 & 57 & 11.6 \\
\hline $25-49$ & 147 & 37.6 & 144 & 29.3 \\
\hline $50-59$ & 42 & 10.7 & 65 & 13.2 \\
\hline $60+$ & 52 & 13.3 & 182 & 37.0 \\
\hline Missing data & 0 & 0.0 & 1 & 0.2 \\
\hline
\end{tabular}

among those aged 15-24 years were due to injuries (64.9\%). This association did not hold true in the case of admissions, as the rate of NCDs and injuries were similar across the age groups.

In the case of deaths there was a significant association between sex and type of emergency condition $\left(\chi^{2}=24.2\right.$, $P<0.01)$. NCDs were more common as the cause of death among females (65.8\%), whereas among males injuries were a more common cause of death (55.6\%) (Table 3). The percentage of males and females who suffered from NCDs was almost equal among admissions (61.5\% and $62.9 \%$ respectively), whereas for injuries the percentage of females admitted was slightly higher than that of males (34.4\% versus $29.9 \%$ ), although the difference was not significant.

\section{Types of NCDs}

Within the category of NCDs, gastrointestinal tract (GIT) disorders were the major cause of both admissions (57.3\%) and deaths (36.6\%) at this surgical emergency hospital (Table 4). Respiratory disorders were the next most common reason for admission (8.7\%). Cancer (17.1\%), cardiac disorders (13.8\%) and neurological disorders (11.8\%) were

\begin{tabular}{|c|c|c|c|c|c|c|c|c|}
\hline \multirow[t]{3}{*}{ Variable } & \multicolumn{4}{|c|}{ Admissions } & \multicolumn{4}{|c|}{ Deaths } \\
\hline & Total & NCDs & Injuries & $\begin{array}{c}\text { Missing } \\
\text { data }\end{array}$ & Total & NCDs & Injuries & $\begin{array}{l}\text { Missing } \\
\text { data }\end{array}$ \\
\hline & No. & & $\%$ & $\%$ & No. & $\%$ & $\%$ & $\%$ \\
\hline \multicolumn{9}{|l|}{ Sex } \\
\hline Male & 231 & 61.5 & 29.9 & 8.7 & 331 & 42.3 & 55.6 & 2.1 \\
\hline Female & 151 & 62.9 & 34.4 & 2.7 & 161 & 65.8 & 32.3 & 1.9 \\
\hline \multicolumn{9}{|l|}{ Age (years) } \\
\hline$<15$ & 70 & 64.3 & 34.3 & 1.4 & 43 & 37.2 & 55.8 & 7.0 \\
\hline $15-24$ & 80 & 65.0 & 28.8 & 6.3 & 57 & 35.1 & 64.9 & 0.0 \\
\hline $25-49$ & 147 & 61.9 & 30.6 & 7.5 & 144 & 45.1 & 54.2 & 0.7 \\
\hline 50-59 & 42 & 61.9 & 33.3 & 4.8 & 65 & 47.7 & 50.8 & 1.5 \\
\hline $60+$ & 52 & 51.9 & 38.5 & 8.6 & 182 & 62.1 & 35.2 & 2.7 \\
\hline Total & 391 & 61.6 & 32.2 & 6.2 & 492 & 50.0 & 48.0 & 2.0 \\
\hline
\end{tabular}

NCD $s=$ noncommunicable diseases. 


\begin{tabular}{|c|c|c|c|c|}
\hline \multirow[t]{2}{*}{ Type of NCD } & \multicolumn{2}{|c|}{$\begin{array}{l}\text { Admissions } \\
\quad(n=241)\end{array}$} & \multicolumn{2}{|c|}{$\begin{array}{c}\text { Deaths } \\
(n=246)\end{array}$} \\
\hline & No. & $\%$ & No. & $\%$ \\
\hline Gastrointestinal tract disorder & 138 & 57.3 & 90 & 36.6 \\
\hline Respiratory disorder & 21 & 8.7 & 11 & 4.5 \\
\hline Cancer & 10 & 4.1 & 42 & 17.1 \\
\hline Cardiac disorder & 9 & 3.7 & 34 & 13.8 \\
\hline Neurological disorder & 7 & 2.9 & 29 & 11.8 \\
\hline Congenital disorder & 7 & 2.9 & 7 & 2.8 \\
\hline Diabetes & 3 & 1.2 & 0 & 0.0 \\
\hline Others & 45 & 18.7 & 22 & 8.7 \\
\hline Missing data & 1 & 0.4 & 0 & 0.0 \\
\hline
\end{tabular}

the most common reasons for death after GIT disorders.

The most commonly observed GIT disorders among admissions $(n=138)$ were appendicitis (48.6\%), cholecystitis

(14.5\%), haemorrhoids (9.4\%) and peptic ulcer (8.7\%). GIT disorders that most often led to death $(n=90)$ were liver cirrhosis (38.9\%) and appendicitis (24.4\%).

\begin{tabular}{|c|c|c|c|c|}
\hline \multirow[t]{2}{*}{ Cause and site of injury } & \multicolumn{2}{|c|}{$\begin{array}{l}\text { Admissions } \\
(n=126)\end{array}$} & \multicolumn{2}{|c|}{$\begin{array}{l}\text { Deaths } \\
(n=236)\end{array}$} \\
\hline & No. & $\%$ & No. & $\%$ \\
\hline \multicolumn{5}{|l|}{ Cause } \\
\hline Fight/stab wound & 8 & 6.3 & 21 & 8.9 \\
\hline Gunshot wound & 1 & 0.8 & 3 & 1.3 \\
\hline Road traffic accident & 11 & 8.7 & 83 & 35.2 \\
\hline Suicide & 1 & 0.8 & 3 & 1.3 \\
\hline Burn & 13 & 10.3 & 17 & 7.2 \\
\hline Fall & 16 & 12.7 & 15 & 6.4 \\
\hline Drowning & 1 & 1.9 & 1 & 0.4 \\
\hline Other & 0 & - & 4 & 1.7 \\
\hline No data & 76 & 57.9 & 89 & 37.7 \\
\hline \multicolumn{5}{|l|}{ Site } \\
\hline Brain & 1 & 0.8 & 3 & 1.3 \\
\hline Head & 8 & 6.3 & 96 & 40.7 \\
\hline Limbs & 64 & 50.8 & 13 & 5.5 \\
\hline Scalp & 2 & 1.6 & 3 & 1.3 \\
\hline Multiple sites & 11 & 8.7 & 65 & 27.5 \\
\hline Femur & 9 & 7.1 & 11 & 4.7 \\
\hline Abdomen & 3 & 2.4 & 2 & 0.9 \\
\hline Chest & 5 & 4.0 & 5 & 2.1 \\
\hline Cervical & 0 & 0.0 & 1 & 0.4 \\
\hline Oesophagus & 0 & 0.0 & 2 & 0.8 \\
\hline Others & 8 & 6.3 & 6 & 2.5 \\
\hline Missing data & 15 & 11.9 & 29 & 12.3 \\
\hline
\end{tabular}

The most common respiratory disorders among admissions $(n=21)$ were tuberculosis (35.1\%), pneumothorax (9.5\%) and bronchitis (9.5\%).

Of the 42 cancer deaths $19.0 \%$ were due to lung cancer, followed by brain tumour (14.3\%), breast cancer (9.5\%) and colon cancer $(9.5 \%)$. Cancers of the bone $(7.3 \%)$, bladder $(4.8 \%)$, stomach (4.8\%), thyroid $(2.4 \%)$, rectosigmoid (2.4\%), mouth (2.4\%), pleura (2.4\%), lymph $(2.4 \%)$, pancreas $(2.4 \%)$, chest wall $(2.4 \%)$, cervical $(2.4 \%)$, oesophagus $(2.4 \%)$ and rectum $(2.4 \%)$ were also observed.Lung (26.1\%), colon (13.0\%), brain $(8.7 \%)$ and bone (8.6\%) were the commonest cancers among males whereas breast $(21.1 \%)$, brain $(21.1 \%)$ and lung (10.5\%) were the commonest cancers among females. Bladder, stomach, thyroid, rectosigmoid, nonHodgkin lymphoma, pancreatic, chest wall and oesophageal cancers were more often recorded among males ( $4.3 \%$ each), while colon, bone, bladder, stomach, oral, pleural, cervical and rectal cancers were more recorded among females ( $5.3 \%$ each).

A great majority of deaths due to cardiovascular disorders $(n=34)$ were due to myocardial infarction (44.1\%) or heart failure (20.5\%).

Another important category of deaths was neurological disorders ( $n$ $=29$ ). The most commonly noted disorder was cerebrovascular accident (48.2\%), followed by hydrocephalus (17.2\%) and haematoma (6.9\%).

\section{Types of injuries}

Within the category of injuries, RTAs were the most frequent reason for death (35.2\%), nearly 4 times higher than for admissions (8.7\%) (Table 5). Fight/ stab wounds were also prominent as a reason for both admissions and deaths (6.3\% and $8.9 \%$ respectively), as were burns ( $10.3 \%$ and $7.2 \%)$ and falls $(12.7 \%$ and $6.4 \%)$.

Injuries affected various parts of the body (Table 5). Injuries to the head (40.7\%) and to multiple sites (27.5\%) 

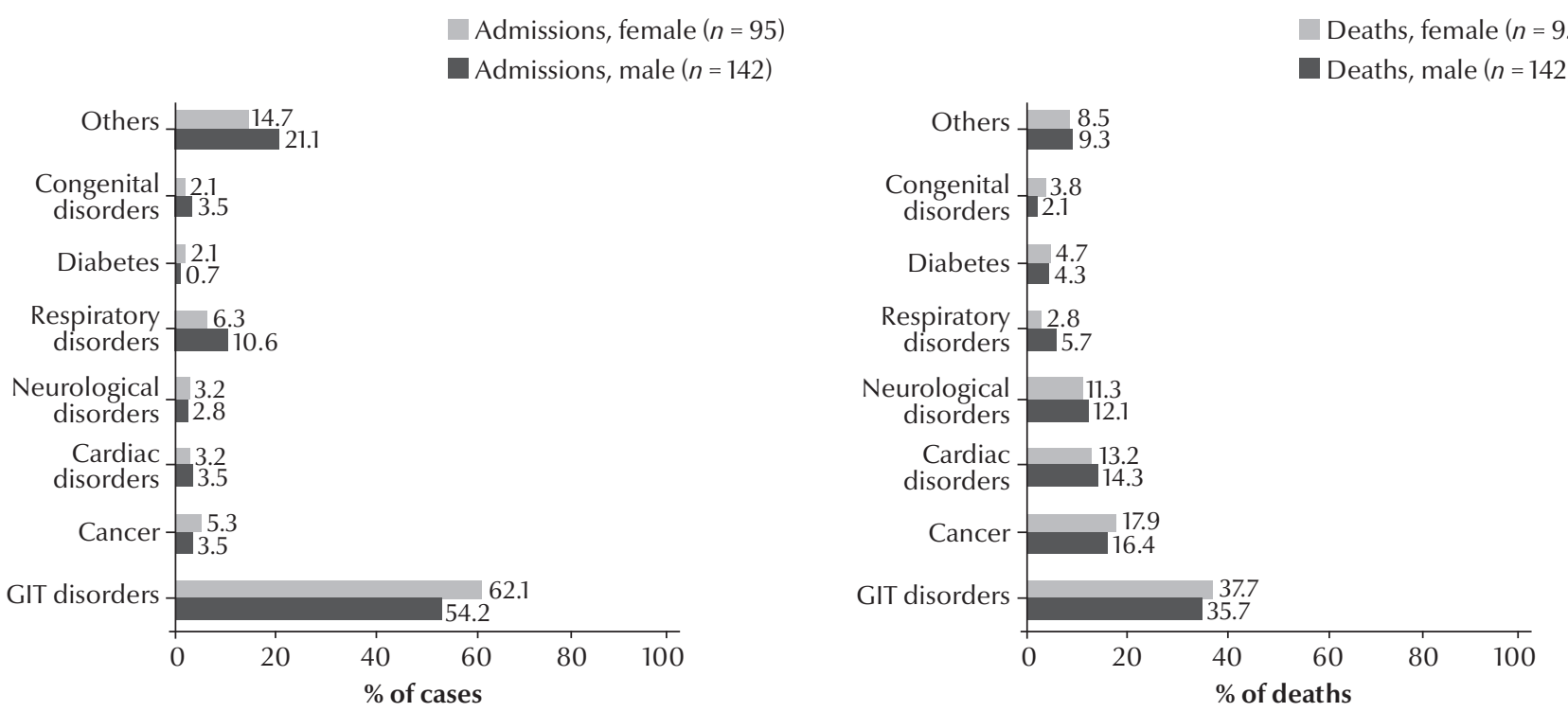

Figure 1 Sex distribution of noncommunicable diseases among the sample of (a) admissions and (b) deaths (GIT = gastrointestinal tract)

were the leading causes of death, whereas injuries to limbs were the major cause of admissions (50.8\%). While injury to the femur was a major reason for admission $(7.1 \%)$, it was a less common reason for death (4.7\%).

\section{Sex differences}

NCDs

Figure 1 shows the sex distribution of the reasons for admissions and deaths for those with NCDs. A higher proportion of those admitted with GIT disorders were females $(62.1 \%)$ compared with males $(54.2 \%)$, whereas a higher percentage of those admitted with respiratory disorders were males (10.6\% vs $6.3 \%$ females). The percentage of those admitted for cancer was higher among females (5.3\%) than males (3.5\%). Respiratory disorders were more common cause of admissions $(n=21)$ and of deaths among males than females (10.6\% versus $6.3 \%$ and $5.7 \%$ versus $2.8 \%$ respectively).

\section{Injuries}

Figure 2 shows the sex distribution of causes of injury for those admitted and dying, for whom data were available. Injuries resulted from RTAs caused deaths among more males (38.6\%) than females $(23.1 \%)$. The corresponding
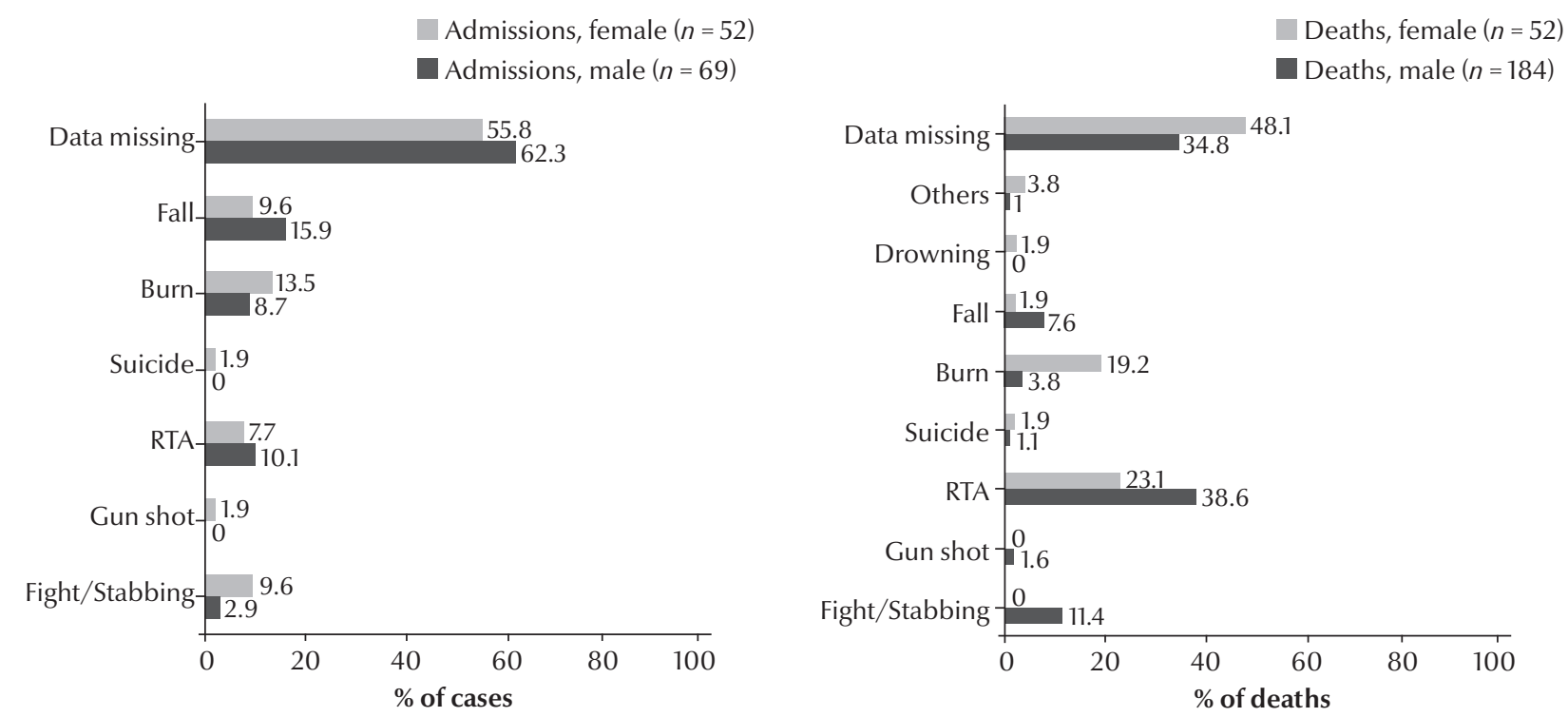

Figure 2 Sex distribution of injuries among the sample of (a) admissions and (b) deaths (RTA = road traffic accident) 
proportions for admissions were $10.1 \%$ and $7.7 \%$ respectively for males and females. After RTAs, the major cause of death among males was fight/stab wounds (11.4\%), whereas for females it was burns (19.2\%). The most common reason for admission among males was falls (15.9\%), RTAs (10.1\%) and burns (8.7\%), whereas for females it was burns (13.5\%), falls (9.6\%) fight/stab wounds (9.6\%) and RTAs (7.7\%).

\section{Age differences}

\section{NCDs}

Table 6 shows the age distribution of the samples of admissions and deaths due to NCDs. There was a weak association between age and type of NCD in the case of males $\left(\chi^{2}=6.9, P<0.1\right)$ and a weaker association in the case of females $\left(\chi^{2}=4.8, P<0.2\right)$. Even though, these significant levels cross the standards set; having such associations was commendable.

GIT disorders, most commonly appendicitis, were the most common reason for admission in all age groups, especially among children $<15$ years $(62.2 \%)$ and those aged 25-49 years (59.3\%). GIT disorders were also the most common cause of death in all age groups, especially those aged $60+$ years (38.9\%) and 25-49 years (38.5\%). The exception was children $<15$ years for whom cancer was the most common cause of death (25.0\%). Cardiac disorders, mostly myocardial infarctions and heart failure, were a more common cause of death among those aged $60+$ years (16.8\%) than other age groups. Respiratory disorders as a cause of death affected more of those aged 60 years and above (5.3\%) and those aged $25-49$ years (4.6\%) than any other age group. After cancer, the major deadly disease among children aged $<15$ years were GIT disorders (18.8\%) and congenital disorders (18.8\%). After GIT disorders, neurological disorders (20.0\%) were the most common reason for death among those aged 15-24 years whereas for those aged 25-49 years it was cancer $(18.5 \%)$ and for those aged 50-59 years it was diabetes $(16.1 \%)$.

\section{Injuries}

Table 7 shows the age distribution of the samples of admissions and deaths due to injuries in cases, where data were available on the cause of injury. There was a significant association between age and reasons for injury when RTAs were analysed against other reasons $\left(\chi^{2}=15.8, P<0.05\right)$. RTAs were the most common causes of death in all age groups. Among those aged < 15 years RTAs (37.8\%) were followed by falls (16.7\%) as a cause of death, while among those aged 15-24 years it was burns (10.8\%) and aged $25-49$ years it was fight/ stab wounds $(20.5 \%)$.

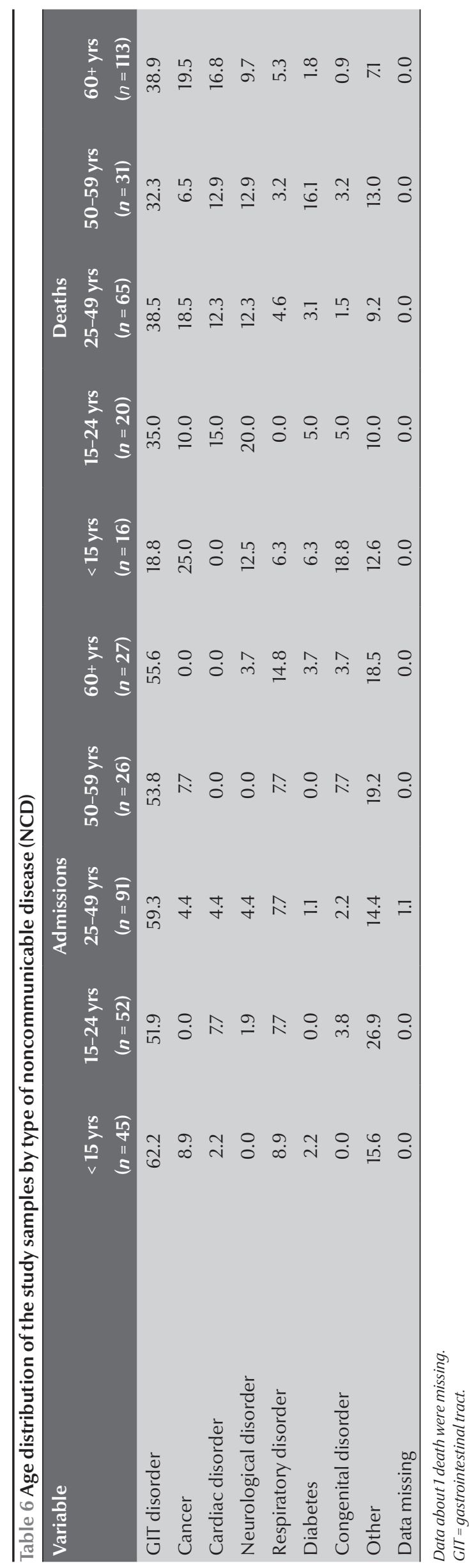




\section{Discussion}

Knowledge of the profile of surgical emergencies obtained from medical records gives insight into the quantity and quality of cases that access the health facility. Data about the at-risk population in terms sex and age, type of problems at admission, type of problems causing death and causes, and type and seriousness of injuries, are useful for the planning and management of infrastructure, manpower and technologies within a health care facility.

Medical emergencies leading to death were biased towards males while among females they were less frequent and less severe. Emergencies affecting males were more life-threatening, whereas those affecting females were more likely to be admissions. While NCDs and injuries caused similar rates of admission to hospital, injuries caused more deaths among males while NCDs caused more deaths among females.

Males were subject to RTAs more often than females, both admissions and deaths. The death toll due to RTAs was also found to be high among females. Vulnerability due to RTAs was high in all age groups.

A distinct age pattern was observed in that the age group 25-49 years was most vulnerable to admissions. Emergencies affecting the oldest age group were more life-threatening. NCDs caused death more often among the old ages, while injuries caused deaths more frequently during adult ages. Deaths due to NCDs increased with increasing age.

Among the causes of NCDs, GIT disorders were responsible for the majority of admission and deaths. Respiratory disorders were a higher proportion of admissions than deaths, but cancer, cardiac disorders and neurological disorders caused more deaths than admissions in the hospital. Among injuries, those due to RTAs were more fatal than injuries due to other causes, such as fighting, gunshots, suicides, burns or fall. The most common sites of injury leading to death were those affecting the head or multiple sites.

\section{Conclusions}

Despite the increasing incidence of trauma due to RTAs and violence in the Middle East and North Africa, accidents and injuries were not the most common type of emergency at our hospital. NCDs were responsible for $50.0 \%$ of deaths and $61.6 \%$ of admissions. Like other societies, the Libya Arab Jamahiriya is witnessing an increasing incidence of NCDs especially cardiovascular disorders, cancer, diabetes, chronic respiratory disorders [12]. Our data are useful therefore not only for highlighting which hospital trauma facilities need to be prioritized but they also have relevance for planning of community health management of NCDs.

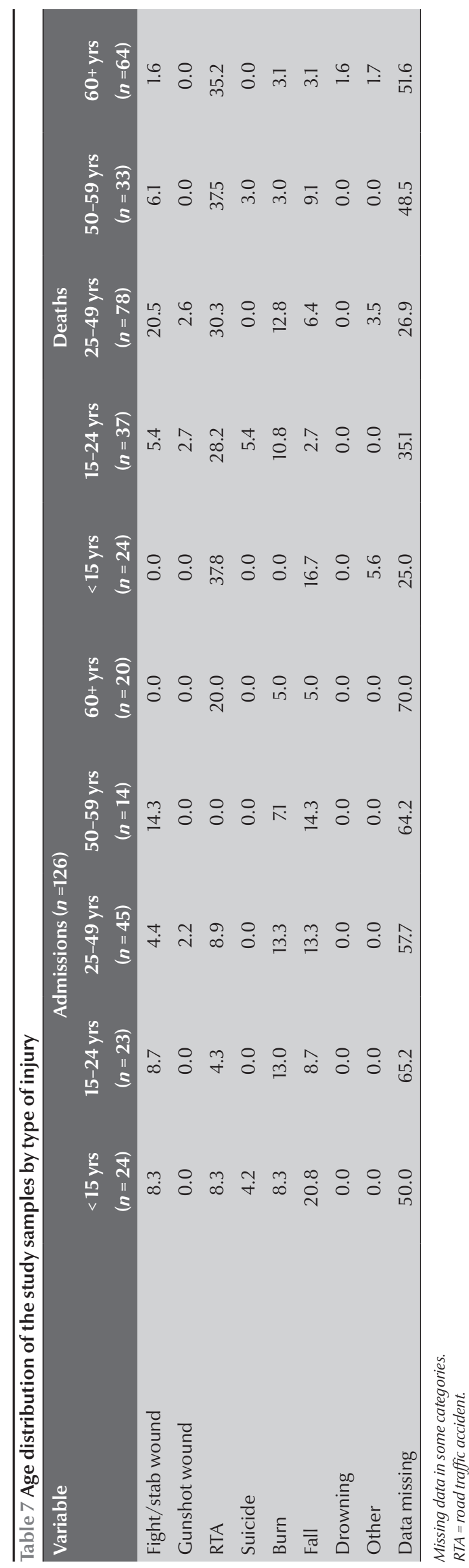




\section{References}

1. A growing crisis in patient access to emergency surgical care. Chicago, American College of Surgeons., Division of Advocacy and Health Policy, 2006.

2. Medical records manual: a guide for developing countries. Manila, World Health Organization Regional Office for the Western Pacific, 2002:59-65.

3. Hoffman EK. Medical record management. Illinois, Physicians Record Company, 1985:445-505.

4. Tabish SA. Hospital and health services administration: principles and practice. Oxford, Oxford University Press, 2005.

5. Zwetsloot-Schonk JHM et al. On the use of a hospital information system in evaluating clinical care: a case report. Informatics for Health and Social Care, 1993, 18(3):243-254.

6. Forster AJ et al. Adverse events following an emergency department visit. Quality and Safety in Health Care, 2007, 16(1):17-22.
7. Singh R, Abudejaja A. Trend and types of disabled persons in Libyan Arab Jamahiriya. International Journal of Rehabilitation Research, 1983, 6(2):153-164.

8. Kadiki OA, Gerryo SE, Khan MM. Diabetes mellitus in Benghazi. Journal of Tropical Medicine and Hygiene, 1988, 91:19-22.

9. Husain MT, Karim QN, Tajuri S. Analysis of infection in a burn ward. Burns, 1989, 15:299-302.

10. Akhtar SS et al. Cancer in Libya-a retrospective study (19811985). African Journal of Medical Sciences, 1993, 22(1):17-24.

11. Investing in health research and development options. Report of the Adhoc Committee on Health Research Relating to Future Intervention Options. Geneva, World Health Organization, 1996 (TDR/Gen/96.1).

12. Country cooperation strategy for WHO and the Libyan Arab Jamahiriya 2005-2009. Cairo, World Health Organization Regional Office for the Eastern Mediterranean, 2006.

\section{Global Initiative for Emergency and Essential Surgical Care (GIEESC)}

WHO GIEESC was established in December 2005 as an international collaboration of Ministries of Health, WHO country offices, local and international organizations and academia. GIEESC is involved in reducing death and disability from road traffic accidents, trauma, burns, falls, pregnancy-related complications, domestic violence, disasters and other surgical conditions. The specific objectives are:

- strengthen capacity to deliver effective emergency surgical care at the first referral level facility, working towards achieving the WHO Millennium Development Goals

- improve the quality of care through safe and appropriate use of emergency and essential surgical procedures and linked equipment in resource limited healthcare facilities

- strengthen existing training and education programmes in safety of essential procedures in low and middle income countries.

Further information about WHO GIEESC can be found at: http:/ /www.who.int/surgery/globalinitiative/en/ 